\title{
Pseudidiomarina piscicola sp. nov., isolated from cultured European seabass, Dicenthrarchus labrax
}

\author{
M. Carmen Macián ${ }^{1} \cdot$ Teresa Lucena $^{1} \cdot$ David R. Arahal ${ }^{1} \cdot$ María A. Ruvira $^{1} \cdot$ Rosa Aznar $^{1} \cdot$ María J. Pujalte $^{1}$ (I)
}

Received: 16 September 2020 / Revised: 28 October 2020 / Accepted: 18 November 2020 / Published online: 7 December 2020

(c) The Author(s) 2020

\begin{abstract}
Strain CECT $9734^{\mathrm{T}}$, a Gram-negative, aerobic, chemoorganotrophic bacterium, motile by polar flagella, was isolated from cultured European seabass, Dicenthrarchus labrax, in Spain. It grows from 5 to $42^{\circ} \mathrm{C}, 6-9 \mathrm{pH}$ and $1-12 \%$ total salinity. Major cellular fatty acids are $\mathrm{C}_{15: 0}$ iso, summed feature $9\left(\mathrm{C}_{17: 1}\right.$ iso $w 9 c / \mathrm{C}_{16: 0} 10$-methyl $)$ and $\mathrm{C}_{17: 0}$ iso. The genome size is $2.5 \mathrm{Mbp}$ and $\mathrm{G}+\mathrm{C}$ content is $49.5 \mathrm{~mol} \%$. Comparative analysis of the $16 \mathrm{~S}$ rRNA gene sequence shows that the strain is a member of Pseudidiomarina, with highest similarities with Pseudidiomarina halophila (97.0\%) and Pseudidiomarina salinarum (96.9\%). Phylogenomic tree based on UBCG program shows $P$. halophila as its closest relative. ANI and in-silico DDH with other Pseudidiomarina spp. are lower than 87 and 20\%, respectively, suggesting that strain CECT $9734^{\mathrm{T}}$ represents a new species, for which we propose the name Pseudidiomarina piscicola sp. nov. and CECT $9734^{\mathrm{T}}\left(=\mathrm{LUBLD} 507 \mathrm{a}^{\mathrm{T}}=\mathrm{LMG}\right.$ $31044^{\mathrm{T}}$ ) as type strain.
\end{abstract}

Keywords Pseudidiomarina $\cdot$ Idiomarina $\cdot$ Idiomarinaceae $\cdot$ Dicenthrarchus labrax $\cdot$ Taxogenomics

\section{Introduction}

Pseudidiomarina is a genus belonging to the family Idiomarinaceae, proposed by Jean et al. 2006. In the following years, several species were described as members of the genus, including the reclassification of two species of Idiomarina. As more species were incorporated, more difficult was their classification, and finally, Taborda et al. (2009) based on the absence of distinguishing phenotypic characteristics, transferred the nine validly named species of the

Communicated by Erko Stackebrandt.

The GenBank/EMBL/DDBJ accession number for the 16S rRNA gene and the whole genome sequences of Pseudidiomarina piscicola CECT $9734^{\mathrm{T}}$ are MN809182 and CACRZB010000001CACRZB010000016, respectively.

Supplementary Information The online version contains supplementary material available at https://doi.org/10.1007/s0020 3-020-02131-3.

María J. Pujalte

maria.j.pujalte@uv.es

1 Departamento de Microbiología y Ecología and Colección Española de Cultivos Tipo (CECT), Universitat de València, València, Spain genus Pseudidiomarina to the genus Idiomarina. Recently, Liu et al. (2018) performed a wide genome-based study of the family Idiomarinaceae, including the genus Aliidiomarina (Huang et al. 2012), and proposed the genus Pseudidiomarina to be restored, establishing a taxonomic reclassification of many species in the family based on genomic analysis. As currently defined, Pseudidiomarina contains sixteen validly named species as stated in https://lpsn.dsmz. de/genus/pseudidiomarina (Parte 2018). One of them, $P$. maritima, has been recently revealed as a later heterotypic synonym of $P$. tainanensis (Liu et al. 2020).

Pseudidiomarina species comprise Gram-negative rods, strictly aerobic and chemoorganotrophic, mesophilic and halophilic which are isolated from seawater and sediments, solar salterns and saline lakes. Only one species, P. aquimaris, was isolated from a marine organism (the coral Isopora pallifera; Chen et al. 2012). Here we address the taxonomic characterization of strain CECT $9734^{\mathrm{T}}$, obtained from the liver of a cultured European seabass specimen, as a basis for the description of a new species of Pseudidiomarina, the first isolated from fish. 


\section{Materials and methods}

\section{Strain isolation and maintenance}

Strain CECT $9734^{\mathrm{T}}$ was isolated from a cultured European seabass, Dicenthrarchus labrax, in Instituto de Acuicultura Torre de la Sal - Consejo Superior de Investigaciones Científicas (IATS-CSIC), Castellón, Spain (4008'16.9"N $0^{\circ} 09^{\prime} 56.0 " \mathrm{E}$ ) on May, 2000. This strain, originally labeled LUBLD50 7a, was obtained from a Marine Agar (MA) plate inoculated with a loop from the liver of a fish specimen and incubated at $26^{\circ} \mathrm{C}$ for 2 days. Once isolated, the strain was maintained as a stab culture in a semisolid Marine Agar screw-capped tube at room temperature in the dark. It was recovered in 2018, and deposited in the Spanish Type Culture Collection (CECT), where it is maintained by freeze-drying under the accession number CECT $9734^{\mathrm{T}}$. A partial 16S rRNA sequence suggested the strain belonged to the genus Pseudidiomarina and might be representative of a new species.

\section{Phenotypic characterization}

Phenotypic characterization of strain CECT $9734^{\mathrm{T}}$ was performed following already described techniques (Pujalte et al. 2018). Cell morphology and motility was determined on wet mounts prepared from $48 \mathrm{~h}$ MA cultures of the strain, using phase contrast microscopy in a Leica DMRB fluorescence microscopy. Colonial morphology was observed in cultures on MA plates after $48 \mathrm{~h}$ of incubation. Temperature range for growth were determined on MA at $5,15,26,30,37,42$ and $45^{\circ} \mathrm{C}$ incubated up to 7 days $\left(5^{\circ} \mathrm{C}\right.$ were incubated up to 21 days). Salinity range was determined on MA diluted to give the desired salinity and supplemented with tryptone and yeast extract to restore original nutritional content (for salinities lower than $3 \%$ ) or MA supplemented with $\mathrm{NaCl}$ as to achieve 6-20\% (w/v) (for higher salinities). Hydrolytic activities on starch, casein, Tween-80 and alginate were determined on solid medium as already described (Pujalte et al. 2018). Oxidase test was performed with Oxoid oxidase strips and catalase was tested with $3 \%(\mathrm{v} / \mathrm{v}) \mathrm{H}_{2} \mathrm{O}_{2}$. API ZYM, API 20NE and API $50 \mathrm{CH} / \mathrm{E}$ were used to determine enzymatic, assimilative and fermentative profiles, after supplementation of inoculating fluids with Marine Cations Supplement (MCS, Farmer and Hickmann-Brenner 2006). Sole carbon and energy sources used for growth were tested as described by Baumann and Baumann (1981).

Fatty acid methyl esters were extracted from cells grown on MA for $48 \mathrm{~h}$ at $26^{\circ} \mathrm{C}$, and following the standard protocols described for the MIDI Microbial Identification
System (Sasser 1990). Analysis of the cellular fatty acid content was performed at CECT using the Microbial Identification Sherlock software.

\section{S rRNA gene sequencing and phylogenetic analysis}

An almost complete 16S rRNA sequence was obtained by PCR amplification and subsequent Sanger sequencing (Arahal et al. 2008), and compared by BLAST, identifying them as belonging to the genus Pseudidiomarina. Moreover, $16 \mathrm{~S}$ rRNA sequence of strain CECT $9734^{\mathrm{T}}$ was annotated in its genome (1549 nt) (see below), and compared with the sequence obtained after amplification, resulting on a $100 \%$ coincidence. Phylogenetic analysis using different treeing methods were done using ARB (Ludwig et al. 2004).

\section{Genome sequencing and analysis}

Genomic DNA was isolated using Gena Bioscience (Diffractia) following the standard protocol recommended by the manufacturer. Genome sequencing of strain CECT $9734^{\mathrm{T}}$, was achieved at Central Service of Support to Experimental Research (SCSIE) of the University of Valencia (Valencia, Spain) using an Illumina Miseq technology with $2 \times 250$ paired-end reads. The reads were analyzed for quality control using FASTQC, a common quality control tool developed by Babraham Bioinformatics to check raw sequencing data. After filtering, the remaining reads were assembled using SPAdes 3.9.0 software (Nurk et al. 2013). A plot, coverage versus length of the contigs, was performed to help in the choice of the parameters for contigs filtering. After the filtration of contigs (500 base pair (bp) length and 10-50 $\times$ kmer coverage). The bioinformatic tool CheckM v1.0.7 (Parks et al. 2015) was used to assess the genome quality prior to annotation using Prokka v1.12 (Seeman 2014) and RAST v2.0 (Rapid Annotation using Subsystem Technology) (Overbek et al. 2014). The process of quality assessment of reads, read-processing, assembly and annotation with Prokka was carried out in Linux OS, other tools were accessed online. The minimal standards for the quality of genome sequences and how they can be applied for taxonomic purposes (Chun et al. 2018) have been observed in this study.

Similarity between genomes was established using in-silico DNA-DNA Hybridization (isDDH) with the Genome-toGenome Distance Calculator (GGDC 2.0) (Meier-Kolthoff et al. 2013) and Average Nucleotide Identity (ANI) index (Richter et al. 2015). Phylogenomic analysis was performed with UBCG (Up-to-date Bacterial Core Gene) using both nucleotide and aminoacidic sequences. UBCG is based on the analysis of 92 universal bacterial core gene sequences (Na et al. 2018). 


\section{Results and discussion}

Morphological, biochemical, and physiological traits of strain CECT $9734^{\mathrm{T}}$ are detailed in the species description and appear in Table 2 and in the Supplementary Table 2.

Two colony types were frequently seen, one transparent and other opaque, of the same size and form. Both colony types were submitted to 16S RNA gene sequencing and resulted identical.

Strain showed low reactivity: it did not grow on any carbon and energy source tested on Basal Medium Agar and it was not able to oxidize or ferment any carbohydrate in API $50 \mathrm{CH} / \mathrm{E}$, even though the inoculation fluid was supplemented with marine salts Detailed results are shown in the species description.

Strain CECT $9734^{\mathrm{T}}$ grows in the presence of marine salts, it did not grow on media supplemented only with $\mathrm{NaCl}$. Salinity range was 1-12\% (on Marine Agar diluted / supplemented with $\mathrm{NaCl}$ ); growth at $15 \%$ salinity was scarce and no growth was obtained at $0.5 \%$ or $18 \%$ or higher salinity. The temperature range for growth was $5-42^{\circ} \mathrm{C}(26-30$ ${ }^{\circ} \mathrm{C}$ optimum) and $\mathrm{pH}$ range was $6-9$ (optimum: $7-8$ ). No growth was obtained at $\mathrm{pH} 5.0$ or less.

Major fatty acids were $\mathrm{C}_{15: 0}$ iso (21.6\%), Summed Feature $9\left(\mathrm{C}_{17: 1}\right.$ iso $\omega 9 c / \mathrm{C}_{16: 0} 10$-methyl) (18.5\%) and $\mathrm{C}_{17: 0}$ iso (14.8\%), with minor amounts of $\mathrm{C}_{16: 0}(9.0 \%)$, Summed Feature $3\left(\mathrm{C}_{16: 1} \omega 7 c / \omega 6 c\right)(6.9 \%), \mathrm{C}_{11: 0}$ iso $3 \mathrm{OH}(5.1 \%)$ and Summed Feature $8\left(\mathrm{C}_{18: 1} \omega 7 c / \omega 6 c\right)(4.9 \%)$ (Supplementary Table S1).

The comparison of the 16S rRNA genome derived gene sequence with those of the type strains in the genus Pseudidiomarina using EzBioCloud identification tool (Yoon

Table 1 In silico DNA-DNA hybridization (isDDH) values and Average Nucleotide Identify (ANI) index relating $P$. piscicola $\mathrm{CECT}$ $9734^{\mathrm{T}}$ to Pseudidiomarina species with available genomes

\begin{tabular}{|c|c|c|}
\hline Species- strain & is $\mathrm{DDH}$ & ANIm \\
\hline P. salinarum $\mathrm{ISL}-52^{\mathrm{T}}$ & 17.7 & 84.4 \\
\hline P. aquimaris $\mathrm{SW} 15^{\mathrm{T}}$ & 18.0 & 85.0 \\
\hline P. sediminum DSM $21906^{\mathrm{T}}$ & 18.2 & 84.7 \\
\hline P. homiensis $\mathrm{PO}-\mathrm{M} 2^{\mathrm{T}}$ & 19.0 & 84.3 \\
\hline P. planktonica $\mathrm{TS}-\mathrm{T} 11^{\mathrm{T}}$ & 17.5 & 83.9 \\
\hline P. aestuarii KYW314 ${ }^{\mathrm{T}}$ & 18.6 & 84.8 \\
\hline P. taiwanensis $\mathrm{PIT} 1^{\mathrm{T}}$ & 18.9 & 86.1 \\
\hline P. halophila $\mathrm{BH} 195^{\mathrm{T}}$ & 18.9 & 83.1 \\
\hline P. insulisalsae CVS-6 ${ }^{\mathrm{T}}$ & 17.6 & 83.6 \\
\hline P. indica CGMCC $1.10824^{\mathrm{T}}$ & 18.8 & 85.2 \\
\hline P. donghaiensis $908033^{\mathrm{T}}$ & 19.4 & 86.3 \\
\hline P. woesei DSM $27808^{\mathrm{T}}$ & 19.3 & 86.2 \\
\hline P. tainanensis $\mathrm{PIN} 1^{\mathrm{T}}$ & 19.2 & 85.2 \\
\hline
\end{tabular}

et al. 2017) showed that strain CECT $9734^{\mathrm{T}}$ was related to Pseudidiomarina halophila ( $97.0 \%$ sequence similarity), $P$. salinarum $(96.9 \%), P$. homiensis $(96.7 \%)$ and $P$. aquimaris $(96.7 \%)$. Phylogenetic tree based on 16S rRNA gene sequences, constructed using Neighbor Joining (NJ) method, show strain CECT $9734^{\mathrm{T}}$ within the species of the genus Pseudidiomarina (Fig. 1), with P. halophila as its closest relative.

The draft genome of strain CECT $9734^{\mathrm{T}}$ has an estimated size of $2.5 \mathrm{Mb}$, similar to the sizes found among Idiomarinaceae species, which are always below $3.1 \mathrm{Mb}$ (Liu et al. 2018). The $\mathrm{G}+\mathrm{C}$ content of the genome is $49.5 \mathrm{~mol} \%$. It is composed of 16 contigs with a N50 value of 441,728 nucleotides and final assembly coverage of $259 \times$. CheckM results of contamination and completeness were $0.0-98.99 \%$, respectively. It contains 2360 protein coding sequences and 54 RNA genes, including a single rRNA operon and 51 tRNAs.

The annotated genome of CECT $9734^{\mathrm{T}}$ contains a gene coding for octaprenyl diphosphate synthase, suggesting that it is able to synthetize ubiquinone 8 (Q8), the most abundant respiratory quinone in the family Idiomarinaceae. It also contains genes coding for cardiolipin synthase, the enzyme responsible for diphosphatidyl glycerol (DPG) production and phosphatidylserine decarboxylase, which allows synthesis of phosphatidyl ethanolamine (PE). Along with phospahtidyl glycerol (PG), these are the major identified polar lipids of the genus Pseudidiomarina.

Although the strain was originally isolated from the liver of a fish, the genome of CECT $9734^{\mathrm{T}}$ does not contain any virulence or disease-related genes, and none of the protein secretion systems that have been related to pathogenicity is present in its genome. Siderophores are also absent. Eleven genes of a type IV pilus are present as well as multidrug resistance efflux pump component genes and several genes involved in copper, zinc, cobalt, cadmium and mercury resistance.

Genome of strain CECT $9734^{\mathrm{T}}$ is related to their closer relatives by ANI values of less than $87 \%$ and insilico DDH values lower than 20\% (Table 1); both values are below the established cut-off figures for prokaryotic species delineation based on genomic data. UBCG-based phylogenomic trees confirm the relationships already displayed in the 16S rRNA gene based tree, with CECT $9734^{\mathrm{T}}$ as a part of the genus Pseudidiomarina and P. halophila as its closer relative (Fig. 2, Supplementary Figure S2). The three genera conforming the family are clearly defined both in the genomic nucleotide- and aminoacidbased trees, in complete agreement with the findings of Liu et al. 2018. A recently described species, Pseudidiomarina gelatinasegens ( $\mathrm{Li}$ et al. 2020) was not included in the trees, but the similarity of its $16 \mathrm{~S}$ rRNA gene to the 
Fig. 1 Phylogenetic reconstruction based on the 16S rRNA gene using the Neighbor joining method. Sequence accession numbers are given in parentheses. Bar indicates number of substitutions per position
Fig. 2 Phylogenomic tree generated with UBCG (Na et al., 2018) using aminoacids sequences. The numbers at the nodes indicate the Gene Support Index (GSI, maximal value is 92). Genome accession numbers are indicated in parentheses. Bar, 0.05 substitutions per position
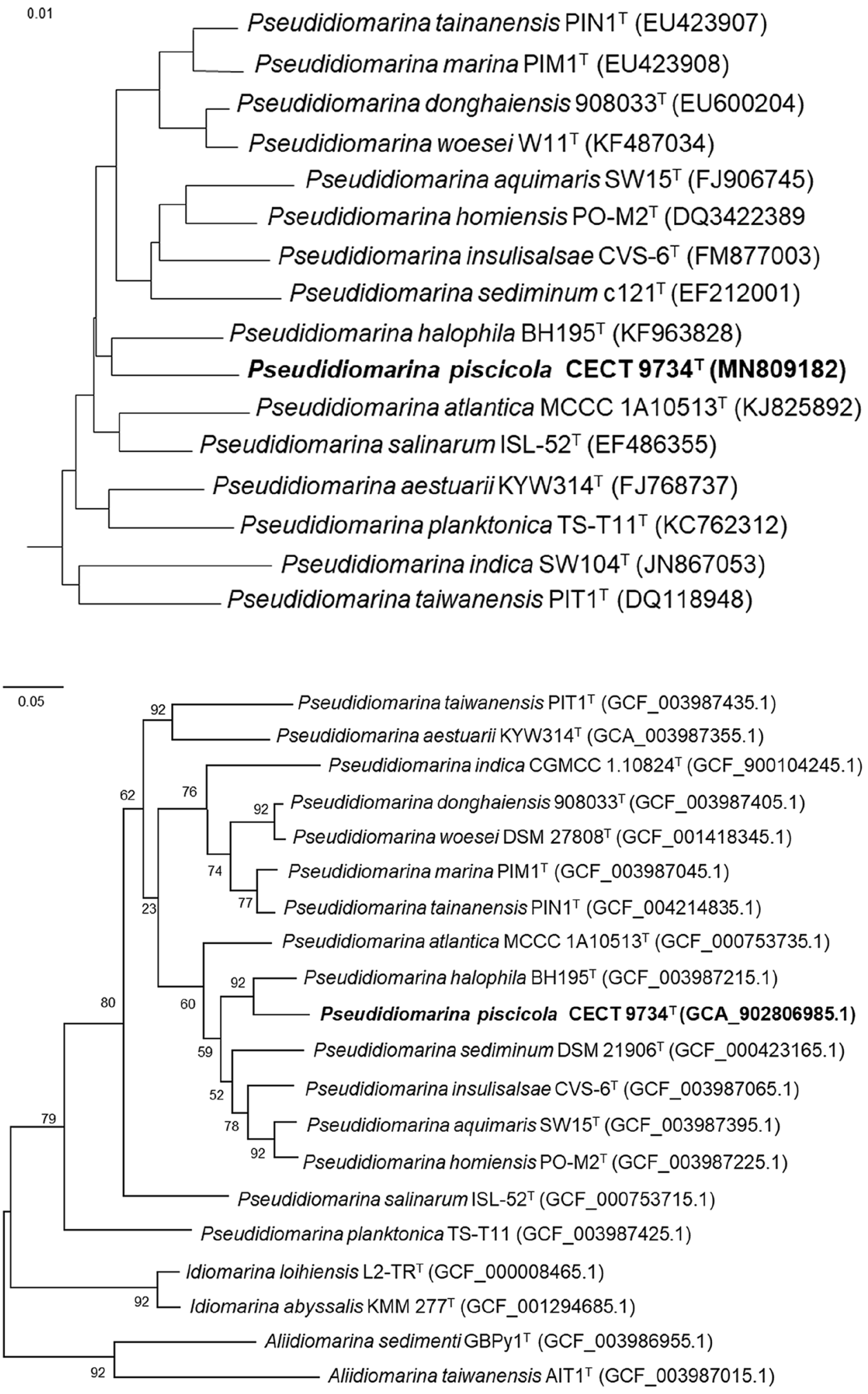
Table 2 Differential characteristics between Pseudidiomarina piscicola CECT $9734^{\mathrm{T}}$ and its closest relatives

\begin{tabular}{llll}
\hline & 1 & 2 & 3 \\
\hline Motility & + & - & + \\
pH range & $6.0-9.0$ & $3.5-10.5$ & $6.0-8.0$ \\
Urea hydrolysis & - & + & - \\
Gelatin hydrolysis & + & + & - \\
Esculin hydrolysis & - & + & - \\
Enzymatic activities on API ZYM & & & + \\
Estearase (C4), Esterase lipase (C8), Trypsin, $\alpha$-Chymotrypsin & - & + & - \\
$\quad$ Valine arylamidase, Cystine arylamidase, Naphthol-AS-BI-phos- & - & + & + \\
$\quad$ phohydrolase, $\beta$-glucosidase & & & \\
$\quad \alpha$-mannosidase & - & & - \\
Acid from (API 50CH) & & & + \\
D-fructose, amygdalin, arbutin, cellobiose, sucrose, trehalose & - & +
\end{tabular}

1: P. piscicola sp. nov. CECT $9734^{\mathrm{T}}$ (this study); 2: P. halophila $\mathrm{BH} 195^{\mathrm{T}}$ (Jean et al. 2006); 3: P. salinarum ISL-52 ${ }^{\mathrm{T}}$ (Yoon et al. 2007). + : positive; - negative. All strains are positive for alkaline phosphatase and leucine aryl amidase. All strains are negative for acidic phosphatase, lipase (C14), $\alpha$-galactosidase, $\beta$-galactosidase, $\beta$-glucuronidase, $\alpha$-glucosidase, $N$-acetyl- $\beta$-glucosaminidase, $\alpha$-fucosidase one of CECT $9734^{\mathrm{T}}$ is lower enough $(96.0 \%)$ to preclude species level relationships between them.

Thus, both phylogenetic and genomic information point to the novelty of CECT $9734^{\mathrm{T}}$ as representative of a yet undescribed Pseudidiomarina species.

Finally, from a phenotypic point of view, the strain displays the main characteristics of genus Pseudidiomarina (as emended by Liu et al. 2018). On the other hand, the strain displays several phenotypic traits that allow discrimination of CECT $9734^{\mathrm{T}}$ from other species in the genus. These differences affect $\mathrm{pH}$ range, urea, esculin and gelatin hydrolysis and enzymes acting on lipids, polypeptides and carbohydrates. Table 2 shows characteristics differentiating CECT $9734^{\mathrm{T}}$ from the two species most similar in 16S rRNA gene sequence.

In consequence, we propose to recognize the strain as representative of a new, yet unnamed species of the genus Pseudidiomarina, with the name of Pseudidiomarina piscicola sp. nov. and CECT $9734^{\mathrm{T}}\left(=\mathrm{LUBLD} 507 \mathrm{a}^{\mathrm{T}}=\mathrm{LMG}\right.$ $\left.31044^{\mathrm{T}}\right)$ as the type strain of the species.

\section{Description of Pseudidiomarina piscicola sp. nov.}

Pseudidiomarina piscicola (pis.ci'co.la. L. n. piscis fish; L. suff. -cola dweller; N.L. n. piscicola, fish -dweller).

Cells are Gram-reaction negative rods, motile by a polar flagellum. Colonies on Marine Agar are regular, convex, with regular border and non-pigmented. May present opaque and transparent colony variants. Cells do not accumulate polyhydroxybutyrate (PHB). Aerobic chemoorganotrophic bacterium, unable to ferment carbohydrates. Oxidase and catalase positive. Grows from $5-42^{\circ} \mathrm{C}$, but not at $45^{\circ} \mathrm{C}$ (optimum $26-30{ }^{\circ} \mathrm{C}$ ) and from 1 to $12 \%$ salinity but not at 0.5 or lower, or $18 \%$ or higher. Values of $\mathrm{pH}$ supporting growth are 6.0-9.0, with optimal growth at 7-8. Reduces nitrates to nitrites but not to $\mathrm{N}_{2}$. It does not produce indole. Hydrolyzes gelatin but not urea, esculin, starch, casein, Tween 80 or alginate. Does not assimilate glucose, arabinose, mannose, mannitol, N-acetyl-glucosamine, maltose, gluconate, caprate, adipate, malate, citrate or phenylacetate in API 20NE. Negative for arginine dihydrolase, lysine decarboxylase and ornithine decarboxylase activities. Unable to grow on any of the following sole carbon and energy sources: D-xylose, L-arabinose, D-mannose, D-cellobiose, sucrose, D-melibiose, lactose, D-sorbitol, D-gluconate, D-glucuronate, 2-oxoglutarate, 3-hydroxybutyrate and putrescine. Unable to oxidize or ferment any carbohydrate in API 50CH/E strips. Positive for alkaline phosphatase and leucine arylamidase activities but negative for estearase $\mathrm{C} 4$, estearase lipase C8, lipase C14, valine arylamidase, cystine arylamidase, trypsin, $\alpha$-chymotrypsin, acidic phosphatase, naphthol-ASBI-phosphohydrolase, $\alpha$-galactosidase, $\beta$-galactosidase, $\beta$-glucuronidase, $\alpha$-glucosidase, $\beta$-glucosidase, $\mathrm{N}$-acetyl $\beta$-glucosaminidase, $\alpha$-mannosidase and $\alpha$-fucosidase in API ZYM.

Major cellular fatty acids are $\mathrm{C}_{15: 0}$ iso, Summed Feature $9\left(\mathrm{C}_{17: 1}\right.$ iso $\omega 9 c / \mathrm{C}_{16: 0} 10$-methyl $)$ and $\mathrm{C}_{17: 0}$ iso. $\mathrm{G}+\mathrm{C}$ molar content is $49.5 \mathrm{~mol} \%$.

Type strain is CECT $9734^{\mathrm{T}}\left(=\mathrm{LUBLD} 507 \mathrm{a}^{\mathrm{T}}=\mathrm{LMG}\right.$ $31044^{\mathrm{T}}$ ), it was isolated from liver of a cultured seabass (Dicentrarchus labrax). The accession numbers of $16 \mathrm{~S}$ rRNA gene sequence and draft genome of the type strain are MN809182 and CACRZB01, respectively. The type strain genome size is $2.5 \mathrm{Mbp}$.

Author contributions MCM and MJP designed the study, MCM, MJP and MAR performed the phenotypic characterization, TL, DRA and 
RA performed genomic and phylogenetic characterization, MJP and MCM drafted the manuscript. All authors read, revised and approved the final manuscript.

Funding Partial financial support was received from UVINV-AE19-1199655 grant of the Universitat de València and AICO/2020/181 grant of the Generalitat Valenciana to MJP.

\section{Compliance with ethical standards}

Conflict of interest The authors declare that there are no conflicts of interest.

Ethical approval This study does not include any experimental procedure performed on humans or animals.

Open Access This article is licensed under a Creative Commons Attribution 4.0 International License, which permits use, sharing, adaptation, distribution and reproduction in any medium or format, as long as you give appropriate credit to the original author(s) and the source, provide a link to the Creative Commons licence, and indicate if changes were made. The images or other third party material in this article are included in the article's Creative Commons licence, unless indicated otherwise in a credit line to the material. If material is not included in the article's Creative Commons licence and your intended use is not permitted by statutory regulation or exceeds the permitted use, you will need to obtain permission directly from the copyright holder. To view a copy of this licence, visit http://creativecommons.org/licenses/by/4.0/.

\section{References}

Arahal DR, Sánchez E, Macián MC, Garay E (2008) Value of recN sequences for species identification and as a phylogenetic marker within the family "Leuconostocaceae". Int Microbiol 11:33-39

Baumann P, Baumann L (1981) The marine gram-negative eubacteria: genera Photobacterium, Beneckea, Alteromonas, Pseudomonas and Alcaligenes. In: Starr MP, Stolp H, Trueper HG, Balows A and Schleger H. Berlin and Heidelberg (eds) The prokaryotes 2 Springer 1302-1331.

Chen MH, Sheu SY, Chen CA, Wang JT, Chen WM (2012) Idiomarina aquimaris sp. nov., isolated from thereef-building coral Isopora palifera. Int J Syst Evol Microbiol 62:1536-1542

Chun J, Oren A, Ventosa A, Christensen H, Arahal DR, da Costa MS et al (2018) Proposed minimal standards for the use of genome data for the taxonomy of prokaryotes. Int J Syst Evol Microbiol 68:461-466

Farmer JJ III, Hickman-Brenner FW (2006) The Genera Vibrio and Photobacterium. In: Dworkin M, Falkow S, Rosenberg E, Schleifer K-H, Stackebrandt E (eds) The prokaryotes, a handbook on the biology of bacteria. 3rd edn 6 508-563

Huang SP, Chang HY, Chen JS, Jean WD, Shieh WY (2012) Aliidiomarina taiwanensis gen. nov., sp. nov., isolated from shallow coastal water. Int J Syst Evol Microbiol 62:155-161

Jean WD, Shieh WY, Chiu HH (2006) Pseudidiomarina taiwanensis gen. nov., sp. nov., a marine bacterium isolated from shallow coastal water of An-Ping Harbour, Taiwan, and emended description of the family Idiomarinaceae. Int J Syst Evol Microbiol 56:899-905

Li A, Zhang M, Xu S, Chen M, Yao Q, Zhu HH (2020) Pseudidiomarina gelatinasegens $\mathrm{sp}$. nov., isolated from surface sediment of the terra nova bay. Antarctica Int J Syst Evol Microbiol 70:708-714

Liu Y, Lai Q, Shao Z (2018) Genome-based analysis reveals the taxonomy and diversity of the Family Idiomarinaceae. Front Microbiol 9:2453
Liu Y, Lai Q, Shao Z, Zhu HH (2020) Pseudidiomarina maritima Wu et al. 2009 is a later heterotypic synonym of Pseudidiomarina tainanensis Jean et al. 2009 and emended description of the species. Int J Syst Evol Microbiol 69:3765-3768

Ludwig W, Strunk O, Westram R, Richter L, Meier H et al (2004) ARB: a software environment for sequence data. Nucl Acids Res 32:1363-1371

Meier-Kolthoff JP, Auch AF, Klenk HP, Göker M (2013) Genome sequence-based species delimitation with confidence intervals and improved distance functions. BMC Bioinformatics 14:60

Na SI, Kim YO, Yoon SH, Ha SM, Baek I, Chun J (2018) UBCG: upto-date bacterial core gene set and pipeline for phylogenomic tree reconstruction. J Microbiol 56:281-285

Nurk S, Bankevich A, Antipov D, Gurevich AA, Korobeynikov A, Lapidus A, et al. (2013) Assembling genomes and mini-metagenomes from highly chimeric reads. In: Deng M., Jiang R., Sun F., Zhang X. (eds) Research in computational molecular biology. RECOMB. Lecture notes in computer science 7821. Springer, Berlin, Heidelberg

Overbeek R, Olson R, Pusch GD, Olsen GJ, Davis JJ, Disz T et al (2014) The SEED and the rapid annotation of microbial genomes using subsystems technology (RAST). Nucleic Acids Res 42:D206-D214

Parks DH, Imelfort M, Skennerton CT, Hugenholtz P, Tyson GW (2015) CheckM: assessing the quality of microbial genomes recovered from isolates, single cells and metagenomes. Genome Res 25:1043-1055

Parte AC (2018) LPSN: list of prokaryotic names with standing in nomenclature (bacterio.net), 20 years on. Int.1. J Syst and Evol Microbiol 68:1825-1829

Pujalte MJ, Lucena T, Rodrigo-Torres L, Arahal DR (2018) Comparative genomics of Thalassobius including the description of Thalassobius activus sp. nov., and Thalassobius autumnalis sp. nov. Front Microbiol 8:2645

Richter M, Rosselló-Móra R, Glöckner FO, Peplies J (2015) JSpeciesWS: a web server for prokaryotic species circumscription based on pairwise genome comparison. Bioinformatics 32:929-931

Sasser M. (1990) Identification of bacteria by gas chromatography of cellular fatty acids, MIDI Technical Note 101. Newark: DE: MIDI Inc

Seemann T (2014) Prokka: rapid prokaryotic genome annotation. Bioinformatics 30:2068-2069

Taborda M, Antunes A, Tiago I, Veríssimo A, Nobre MF, Da Costa MS (2009) Description of Idiomarina insulisalsae sp. nov., isolated from the soil of a sea salt evaporation pond, proposal to transfer the species of the genus Pseudidiomarina to the genus Idiomarina and emended description of the genus Idiomarina. Syst Appl Microbiol 32:371-378

Yoon SH, Ha SM, Kwon S, Lim J, Kim Y, Seo H et al (2017) Introducing EzBioCloud: a taxonomically united database of $16 \mathrm{~S}$ rRNA and whole genome assemblies. Int J Syst Evol Microbiol 67:1613-1617

Yoon JH, Jung SY, Jung YT, Oh TK (2007) Idiomarina salinarum sp. nov., isolated from a marine solar saltern in Korea. Int J Syst Evol Microbiol 57 (11):2503-2506

Publisher's Note Springer Nature remains neutral with regard to jurisdictional claims in published maps and institutional affiliations. 